\title{
Is Inhaled Furosemide A Potential Therapeutic For COVID-19?
}

\author{
Anja Brennecke ${ }^{1}$, Laura Villar ${ }^{1}$, Zhiyu Wang ${ }^{1}$, Lisa Doyle $^{1}$, Autumn Meek ${ }^{1}$, Mark Reed ${ }^{1}$, \\ Christopher Barden ${ }^{1}$, and Donald Weaver ${ }^{1}$ \\ ${ }^{1}$ Krembil Research Institute
}

May 4, 2020

\begin{abstract}
The potentially lethal COVID-19 infection caused by the novel Severe Acute Respiratory Disease Coronavirus-2 (SARS-CoV-2) has evolved into a global crisis. There are two major processes that lead to the morbidity and mortality of this disease: initially the viral infection, followed by a host inflammatory response that frequently results in excessive secretion of inflammatory cytokines (e.g. IL-6, IL-8, IL-10, TNF $\alpha$ ), developing into a self-targeting toxic "cytokine storm" in which the lungs fill with inflammatory secretions causing critical pulmonary tissue damage. Even though the search for a vaccine and anti-viral agents has already been initiated, the de novo development of a safe, COVID-19 specific solution may take years; regrettably, the need for a therapeutic that is available immediately is growing daily. Therefore, repurposing an already approved drug offers a promising approach to address this urgent need. A truly effective therapeutic, however, should be available not only for the single individual in a developed country, but also for the many people in developing countries. As presented in this review, inhaled furosemide, a small molecule capable of inhibiting IL-6, IL- 8 and TNF $\alpha$ within the lung, may be an agent capable of treating the COVID-19 cytokine storm in both resource-rich and developing countries. Furosemide is a "repurpose-able" small molecule therapeutic, that is safe, easily synthesized, handled and stored, and is available in reasonable quantities worldwide.
\end{abstract}

\section{Introduction}

Over the past 20 years, two previous coronavirus infections, Severe Acute Respiratory Syndrome (SARS$\mathrm{CoV}$ ) and Middle Eastern Respiratory Syndrome (MERS-CoV), emerged as potential epidemics. More recently in December 2019, the novel Severe Acute Respiratory Disease Coronavirus-2 (SARS-CoV-2) appeared in Wuhan, China, causing the previously unknown and potentially lethal COVID-19 infection; it has subsequently spread worldwide.[1],[2] Over the first four months of 2020, COVID-19 has evolved into a global crisis, far exceeding the impact of SARS-CoV and MERS-CoV. As of April 27 2020, there have been over 3 million infections reported worldwide, stressing not only healthcare systems but also the global economy. An effective curative treatment for COVID-19 has not been identified.[3],[4]

As evidenced by the word pandemic, COVID-19 is a global problem requiring a globally available solution. Although mesenchymal stem cell approaches, biologics and other complex molecules need to be studied, they do not represent a global solution, especially in the short term. Moreover, even in developed countries, equitable access to expensive therapies may not be readily available to all socioeconomic groups. COVID19 is not only a disease of individuals, it is a disease affecting our global healthcare system and our global economic stability. Accordingly, a truly effective therapeutic must address this full societal and socioeconomic hierarchy, from the single individual in a developed country, to the many people in developing countries. As presented in this review, inhaled furosemide might be an agent that can address some of the needs in both resource-rich and developing countries. 


\subsection{Pathogenesis of COVID-19}

Clinically, COVID-19 is characterized by fever, cough, myalgia and dyspnoea, sometimes evolving into fulminant respiratory failure.[5] Though the pathogenic mechanisms are diverse, there are two major processes that lead to the morbidity and mortality of this disease: initially the viral infection, followed by a host inflammatory response that frequently results in excessive secretion of inflammatory cytokines (e.g. IL-2, IL-6, IL-8, IL-10 and TNF $\alpha$ ). This immune response can develop into a self-targeting toxic "cytokine storm" in which the lungs fill with inflammatory secretions causing critical damage to pulmonary tissue.[6]-[9] Accordingly, the development of therapeutics for COVID-19 can be divided into two groups: anti-viral and anti-inflammatory. Even though the search for a vaccine and anti-viral agents has already been initiated, the de novo development of a safe, COVID-19 specific solution and its worldwide distribution may take several years; regrettably, the need for a therapeutic that is available immediately is growing daily. Therefore, repurposing an already approved drug may offer a promising approach to address this urgent need.

\subsection{Rationale for a small molecule approach}

Multiple recent clinical studies have been evaluating different biological agents ("biologics") that target specific cytokines. Therapeutics under consideration include tocilizumab and sarilumab, both monoclonal antibodies inhibiting the IL-6 pathway, as well as the TNF $\alpha$ targeting agent adalimumab.[10]-[13] A study from China reported preliminary results showing that treatment with tocilizumab improved the condition of 21 patients such that 19 were discharged within two weeks following treatment, with the remaining patients "recovering well".[11] While these and other promising data are developing around the inhibition of cytokine production by biologics, these therapeutics come with multiple drawbacks for their application to COVID-19. Not only is the production of such large molecules time consuming and expensive and their storage may require facilities not always available in developing countries, but also their penetration into pulmonary tissue may not be sufficient; moreover, they target only one of the several cytokine pathways implicated in the immunopathic diseases processes of COVID-19. Finally, there is also the paradoxical concern that they may make patients prone to secondary infections or other toxicities (hepatotoxicity) when administered systemically.[14] For all these reasons, the application of biological agents in a global pandemic, which also affects developing countries lacking the same resources as developed countries, has its limitations. Consequently, small molecule therapeutics are an attractive alternative, especially potentially "repurpose-

able" known drugs that are safe, available in reasonable quantities worldwide, easily synthesized at low cost and easily handled and stored - such agents should be explored for their therapeutic utility in both developed and developing countries immediately.

\section{Furosemide}

A molecule that fulfils all the above-mentioned criteria is the loop diuretic furosemide (4-chloro-5-sulfamoyl$N$-furfuryl-anthranilate), which has previously been reported to show significant inhibition of the cytokine production associated with activation of the innate immune system.[15] Structurally, furosemide is related to the tryptophan metabolite 3-hydroxyanthranilic acid (3-HAA) which, among other various tryptophan metabolites, acts as endogenous modulator of innate immunity exhibiting anti-inflammatory properties by supressing production of pro-inflammatory cytokines;[16] moreover, analogous to furosemide, other loop diuretics also share this anthranilate structural motif (See Figure 1).

\subsection{Pharmacokinetics and diuretic effect}

Furosemide is a commonly used diuretic listed on the WHO's List of Essential Medicines which comprises the 
safest and most effective drugs readily available worldwide. It is a weak organic acid with low lipophilicity ( $\log \mathrm{P}=2.03$ ).[17] It is $98.6 \pm 0.4 \%$ bound to plasma protein due to its sulfonamide and carboxylic acid moieties which, together with a relatively short half-life of $1.3 \pm 0.8 \mathrm{~h}$ and a low volume distribution $\left(\mathrm{V}_{\mathrm{D}}\right)$ of $0.13 \pm 0.06 \mathrm{~L} \mathrm{~kg}^{-1}$, results in low tissue distribution.[17] Clearance of furosemide is conducted predominantly in the kidneys (85\%) with about half of it being metabolized to glucuronic acid and half being secreted unchanged.[18]

To achieve a diuretic effect, furosemide is administered orally or intravenously, typically at doses of 4080 mg. [19] Furosemide blocks sodium $\left(\mathrm{Na}^{+}\right)$, potassium $\left(\mathrm{K}^{+}\right)$and chloride $\left(\mathrm{Cl}^{-}\right)$reabsorption in the proximal and distal tubules as well as in the ascending limb of Henle's loop and thereby causes diuresis peaking 6090 min after administration with enhanced excretion of sodium, potassium and chloride.[20]-[24] This diuretic effect is achieved by inhibition of the $\mathrm{Na}^{+} / \mathrm{K}^{+} / \mathrm{Cl}^{-}$cotransporters in the nephron, reducing $\mathrm{Na}^{+}$-transport from the luminal side into the basolateral side for reabsorption. [25]

\subsection{Anti-innate immune system properties of furosemide}

In 1988, Bianco and co-workers noted that exercise-induced bronchoconstriction in asthmatic patients was alleviated by inhaled furosemide, but not by orally administered furosemide.[26] Since then, furosemide has been investigated as a possible treatment for symptomatic dyspnoea, initially based on the assumption that the size of edematous airway mast cells would be reduced by cellular diuresis thereby improving airway patency.[27],[28] However, multiple mechanistic studies have reported that furosemide's effects on dyspnoea is not related to a local diuretic activity mediated via the $\mathrm{Na}^{+} / \mathrm{K}^{+} / \mathrm{Cl}^{-}$cotransporter; [29] instead, current evidence indicates that this therapeutic effect arises from reduced secretion of pro-inflammatory cytokines, specifically IL-6, IL-8 and TNF $\alpha$. In two studies by Yuengsrigul et al. $(1996,1999)$ peripheral blood mononuclear cells (PBMCs) from healthy subjects were isolated, stimulated with lipopolysaccharide (LPS) and treated with furosemide. It was found that levels of IL-6, IL-8 and TNF $\alpha$ from furosemide treated cells were significantly reduced compared to PBMCs not treated with furosemide.[30] Similar results by Xu et al. (2006) report reduced production of the pro-inflammatory cytokines IL-6 and TNF $\alpha$ in pre-eclamptic placentas and PBMCs.[31] Also, our group has recently shown inhibition of pro-inflammatory cytokine production as well as promotion of anti-inflammatory markers by furosemide in multiple macrophage cell lines of the human innate immune system. [32] These findings are supported by multiple clinical trials studying the reduced secretion of pro-inflammatory cytokines in patients with bronchopulmonary dysplasia, [33] tachypnoea, [34],[35] and chronic lung disease[36],[37] upon administration of inhaled furosemide.

Other clinical studies have reported beneficial anti-inflammatory and symptomatic effects of inhaled furosemide in experimentally induced air hunger and breathing discomfort. In a double-blind, placebo-controlled clinical trial by Grogono et al. (2018), the effect of $40 \mathrm{mg}$ inhaled furosemide was tested on the sensation of experimentally induced air hunger and work effort. It was found that air hunger in healthy individuals is significantly relieved by inhaled furosemide, while this was not the case with inhaled saline control.[38] These results support the study of Moosvai et al. (2007) who had conducted a similar trial on the air hunger sensation; they, too, reported that air hunger is relieved by inhalation of $40 \mathrm{mg}$ furosemide. [39] Yet another study reporting that furosemide alleviates the sensation of dyspnoea was conducted by Nishino and co-workers (2000): in 12 healthy subjects, severe dyspnoeic sensation was induced by breath holding and loaded breathing with a combination of inspiratory resistive load and hypercapnia. It was found that after inhalation of furosemide (and compared to the inhalation of a placebo), total breath holding time was prolonged and respiratory discomfort during loaded breathing developed more slowly.[40] Multiple other studies have reported the positive effects of inhaled furosemide in attenuating bronchoconstriction and asthma attacks, presumably via an anti-inflammatory mechanism.[41]-[45]

In contrast, a single study by Banzett et al. (2017) reported that in 11 healthy volunteers the reduction of breathing discomfort by $80 \mathrm{mg}$ inhaled furosemide was only slightly greater than that of an inhaled saline solution; in fact, both furosemide and saline placebo aerosols alleviated the breathing discomfort to a very 
similar, clinically relevant extent.[46]

\subsection{Anti-viral properties of furosemide}

Besides its anti-inflammatory properties and positive effects in dyspnoea, furosemide has also been shown to exhibit anti-viral properties. Voss et al. (1996) concluded that furosemide inhibited the $\mathrm{Na}^{+} / \mathrm{K}^{+} / 2 \mathrm{Cl}^{-}$ cotransporter and thereby blocked the cytopathic effects of alterations in intracellular cation concentration induced by the human immunodeficiency virus (HIV), a single-stranded, positive-sense, enveloped RNA virus member of the genus Lentivirus, part of the family Retroviridae.[47] In cells infected with a cytopathic strain of $\mathrm{HIV}-1$, the activity of the $\mathrm{Na}^{+} / \mathrm{K}^{+} / 2 \mathrm{Cl}^{-}$cotransporter was significantly increased, leading to a higher $\mathrm{Na}^{+}$and $\mathrm{K}^{+}$concentrations and thereby to an increased cell volume. This pathological swelling can then lead to membrane disruption and ultimately cell death. Inhibition of the $\mathrm{Na}^{+} / \mathrm{K}^{+} / 2 \mathrm{Cl}^{-}$cotransporter by furosemide, however, was able to reduce this pathological process, prolonging the survival of cells by $2-4$ weeks. [47]

Ulug et al. (1989) studied the influence of cation gradients in the release of Sindbis virus, a positivesense, single-stranded RNA virus, from infected cells.[48] The cell volume of Sindbis virus infected cells is reduced and the activity of the $\mathrm{Na}^{+} / \mathrm{K}^{+}$ATPase is decreased, presumably to maintain a higher, intracellular concentration of monovalent cations. Especially in low salt media, but also, with reduced extent, in isotonic media, the treatment of infected cells with furosemide inhibited the release of Sindbis virus from these cells through the inhibition of the $\mathrm{Na}^{+} / \mathrm{K}^{+} / 2 \mathrm{Cl}^{-}$cotransporter.[48] In another study by Hartley et al. (2006), the effect of furosemide-induced inhibition of the $\mathrm{Na}^{+} / \mathrm{K}^{+} / 2 \mathrm{Cl}^{-}$cotransporter in DNA and RNA viruses was explored. According to these authors, DNA viruses are dependent upon $\mathrm{K}^{+}$for replication,[49] thus stopping $\mathrm{K}^{+}$influx by inhibition of the $\mathrm{Na}^{+} / \mathrm{K}^{+} / 2 \mathrm{Cl}^{-}$cotransporter would have broad-spectrum anti-viral effects. While reduced replication was indeed observed for DNA viruses, the replication of the RNA virus was not inhibited.[50] These multiple studies all conclude that the pathologic alteration of intracellular cation concentrations mediated by viral action can be blocked by furosemide through inhibition of the $\mathrm{Na}^{+} / \mathrm{K}^{+} / 2 \mathrm{Cl}^{-}$ cotransporter.

Finally, it is important to note that furosemide's anti-viral activities do not require systemic administration of the drug. Indeed, topical and locally administered furosemide gel has demonstrated efficacy against warts caused by the human papillomavirus.[51]

\subsection{Other diuretics as inhaled anti-inflammatory agents}

Loop diuretics: In addition to furosemide, other diuretics with structural similarities to furosemide's anthranilate molecular core are reported to exhibit analogous anti-inflammatory properties. Hung and co-workers (2018) showed that bumetanide reduced the production of pro-inflammatory cytokines upon direct pulmonary administration, lowered levels of $\mathrm{TNF} \alpha$ in mice and showed anti-inflammatory activity in RAW264.7 cells stimulated by pro-inflammatory lipopolysaccharides (LPS).[52] In another study investigating lung injury induced by ischemia-reperfusion, bumetanide showed a similar effect. Compared to a control group, mice given bumetanide during the reperfusion period were reported to have a lower level of TNF $\alpha$ production.[53] Although bumetanide failed to inhibit sodium metabisulfite(MBS)-induced bronchoconstriction in asthmatic subjects, [54] another loop diuretic, piretanide, is reported to have protective effects against MBS-mediated bronchoconstriction. The protective effect, however, did not correlate with the diuretic properties of piretanide.[55] These findings are supported by work from Bianco et al. in which piretanide was as effective as furosemide in preventing bronchoconstriction induced by ultrasonically nebulized distilled water.[56] Yet another loop diuretic that exhibits effects on cytokine production is azosemide (Hampel et al.; 2018).[57]

Osmotic diuretics: Although not structurally related to furosemide (See Figure 2), other diuretics have also been suggested to have inflammatory properties targeting pulmonary disorders. Mannitol is an osmotic 
diuretic sometimes used to reduce increased intracranial pressure. Inhaled dry powder mannitol has been evaluated as a therapeutic for cystic fibrosis and bronchiectasis.[58],[59] de Nijs et al. (2011) have shown that the therapeutic effect of inhaled mannitol against chronic obstructive pulmonary disease is reflected by favourable alterations in IL-8 and eosinophil biomarkers.[60]

\section{Discussion of inhaled furosemide in COVID-19}

Since the morbidity and mortality of COVID-19 infections arise in part from the toxic overproduction of pro-inflammatory cytokines, the application of anti-inflammatory agents is a mechanistically-sound strategy for treatment development. Furosemide not only inhibits the secretion of multiple cytokines implicated in COVID-19, it has also been shown to provide relief of dyspnea via direct inhalation. Due to its wide-spread use as diuretic, it is well-studied, commonly available globally, and, since it is a small molecule, it can be produced and stored at low cost. When given by inhalation, furosemide is simply dissolved in normal saline solution; therefore, the distribution of furosemide to COVID-19 patients in developed and developing countries will be fast and facile.

However, the administration of furosemide to COVID-19-afflicted people also has several potential drawbacks that need to be considered. First, hypokalemia and electrolyte depletion have been found to be consequences of SARS-CoV-2 induced pathology.[61],[62] Since one of furosemide's main adverse effects is hypokalemia $(3.6 \%)$, this may lead to exacerbating potassium depletion.[63] On the other hand, hypokalemia is a sideeffect of systemically given furosemide. The diuretic effect is anticipated to be very small or even absent upon nebulized inhaled administration.[38] Waskiw-Ford et al. (2018) have reported that diuresis does not occur upon inhalation of furosemide except possibly at doses exceeding $100 \mathrm{mg}$.[64] Nevertheless, patients should also be monitored closely for enhanced production of urine which would accompany the risk of hypokalemia. Another potential problem may arise from the procedure of administering inhaled furosemide - will the resulting aerosols enhance the spread of the SARS-CoV-2 virus to close bystanders. Whilst intubated patients can be given furosemide with reduced risk to those nearby, inhalation by nebulizer mask will cause aerosol development and may thereby promote viral spread if done without physical distancing. This risk, however, can easily be mitigated by appropriate personal protecting equipment in nearby people or simply by having designated inhalation sites that are physically separated from other individuals. Furthermore, since cough is a primary mechanism of disease spread, and since inhaled furosemide decreases coughing, once initiated, inhaled furosemide may contribute to decreased disease spread.

Arguably, inhaled furosemide could be administered at any stage of the COVID-19 disease presentation, from the early phases involving cough, fever and shortness of breath, to the late stages requiring endotracheal intubation. In the early stages, it is possible that furosemide might prevent disease progression to pulmonary failure; in the late stages, it is possible that furosemide might reduce the number of days of required ventilator support.

Administering drugs to any severely ill individual person is not without risk.[65] The potential side-effects of furosemide, including hypokalemia and dehydration, will be minimized by administration through inhalation; nevertheless, these are-side effects that must be considered. In addition, even though cytokine storms are known to play a major role in severe viral pneumonias, the detailed mechanism of hypercytokinemia in COVID-19 is not yet fully delineated.[66] 


\section{Conclusions}

Furosemide is a globally available, inexpensive, well-studied drug that can be readily given by inhalation. Unlike biologics targeting a single cytokine, furosemide has broad spectrum anti-pro-inflammatory activities, targeting IL-6, IL-8 and TNF $\alpha$. It may also have anti-viral effect when given locally, but the relevance of this to the SARS-CoV-2 virus is unproven and purely speculative at this time.

COVID-19 is currently in 210 countries across our planet, in both resource-rich and developing countries. On balance, therapies that are available worldwide for COVID-19 are needed, now - it is a global problem requiring a globally available solution. Inhalation of furosemide has been investigated in the past for a variety of pulmonary disorders, and was found to be safe. Therefore, we suggest an evaluation of inhaled nebulized furosemide in COVID-19 patients as a potential disease modifying therapeutic via a primarily anti-inflammatory mechanism of action.

\section{Acknowledgements}

DFW acknowledges salary support from a Canada Research Chair, Tier 1.

\section{Conflict of Interest}

The authors declare no conflict of interest.

\section{References}

1. Paules CI, Marston HD, Fauci AS. Coronavirus Infections-More Than Just the Common Cold. JAMA. 2020;323(8):707-708.

2. World Health Organization. Coronavirus Disease 2019: Situation Report - 92. 2020.

3. Cascella M, Rajnik M, Cuomo A, Dulebohn SC, Di Napoli R, eds. Features, Evaluation and Treatment Coronavirus (COVID-19). Treasure Island (FL): StatPearls Publishing; 2020.

4. Cortegiani A, Ingoglia G, Ippolito M, Giarratano A, Einav S. A systematic review on the efficacy and safety of chloroquine for the treatment of COVID-19. J Crit Care. 2020.

5. Yang $\mathrm{X}, \mathrm{Yu} \mathrm{Y}, \mathrm{Xu}$ J, et al. Clinical course and outcomes of critically ill patients with SARS-CoV-2 pneumonia in Wuhan, China: a single-centered, retrospective, observational study. Lancet Respir Med. 2020.

6. Conti P, Ronconi G, Caraffa A, et al. Induction of pro-inflammatory cytokines (IL-1 and IL-6) and lung inflammation by Coronavirus-19 (COVI-19 or SARS-CoV-2): anti-inflammatory strategies. J Biol Regul Homeost Agents. 2020;34(2).

7. Huang C, Wang Y, Li X, et al. Clinical features of patients infected with 2019 novel coronavirus in Wuhan, China. The Lancet. 2020;395(10223):497-506.

8. Diao B, Wang C, Tan Y, et al. Reduction and Functional Exhaustion of T Cells in Patients with Coronavirus Disease 2019 (COVID-19). medRvix 2020.02.18.20024364v1; 2020.

9. Qin C, Zhou L, Hu Z, et al. Dysregulation of immune response in patients with COVID-19 in Wuhan, China. Clin Infect Dis. 2020.

10. Peking University First Hospital. Favipiravir Combined with Tocilizumab in the Treatment of Corona Virus Disease 2019. https://ClinicalTrials.gov/show/NCT04310228. 2020.

11. Xu X, Han M, Li T, Sun W, Wang D, Fu B. Effective Treatment of Severe COVID-19 Patients with Tocilizumab. ChinaXiv. 202003.00026v1. 2020. 
12. Pharmaceuticals R, Sanofi. Evaluation of the Efficacy and Safety of Sarilumab in Hospitalized Patients With COVID-19. https://ClinicalTrials.gov/show/NCT04315298. 2020.

13. Zhou L, Xu H. A clinical study for the efficacy and safety of Adalimumab Injection in the treatment of patients with severe novel coronavirus pneumonia COVID-19. (ChiCTR2000030089): Results pending. 2020.

14. Anger F, Wiegering A, Wagner J, et al. Toxic drug-induced liver failure during therapy of rheumatoid arthritis with tocilizumab subcutaneously: a case report. Rheumatology (Oxford). 2017;56(9):1628-1629.

15. Yuengsrigul A, Chin TW, Nussbaum E. Immunosuppressive and cytotoxic effects of furosemide on human peripheral blood mononuclear cells. Ann Allergy Asthma Immunol. 1999;83(6):559-566.

16. Lee W-S, Lee S-M, Kim M-K, et al. The tryptophan metabolite 3-hydroxyanthranilic acid suppresses T cell responses by inhibiting dendritic cell activation. Int Immunopharmacol. 2013;17(3):721-726.

17. Hardman JG, Goodman LS, Gilman AG, eds. Goodman \& Gilman's The pharmacological basis of therapeutics. 10. ed. New York, NY: McGraw-Hill Med. Publ; 2001.

18. Pichette V, Du Souich P. Role of the kidneys in the metabolism of furosemide: its inhibition by probenecid. J Am Soc Nephrol. 1996;7(2):345-349.

19. Brater DC. Diuretic therapy. N Engl J Med. 1998;339(6):387-395.

20. Burg M, Stoner L, Cardinal J, Green N. Furosemide effect on isolated perfused tubules. Am J Physiol. $1973 ; 225(1)$.

21. Berman LB, Ebrahimi A. Experiences with Furosemide in Renal Disease. Proc Soc Exp Biol Med. 1965;118:333-336.

22. Calesnick B, Christensen JA, Richter M. Absorption and excretion of furosemide-S35 in human subjects. Proc Soc Exp Biol Med. 1966;123(1):17-22.

23. Benet LZ. Pharmacokinetics/pharmacodynamics of furosemide in man: a review. J Pharmacokinet Biopharm. 1979;7(1):1-27.

24. Jacobson HR, Kokko JP. Diuretics: sites and mechanisms of action. Annu Rev Pharmacol Toxicol. 1976;16(1):201-214.

25. Odlind B, Beermann B. Renal tubular secretion and effects of furosemide. Clin Pharmacol Ther. 1980;27(6):784-790.

26. Bianco S, Robuschi M, Vaghi A, Pasargiklian M. Prevention of Exercise-Induced Bronchoconstriction by Inhled Frusemide. The Lancet. 1988;332(8605):252-255.

27. Prandota J. Furosemide: progress in understanding its diuretic, anti-inflammatory, and bronchodilating mechanism of action, and use in the treatment of respiratory tract diseases. Am J Ther. 2002;9(4):317-328.

28. Owens D. Nebulized Furosemide for the Treatment of Dyspnea. J Hosp Palliat Nurs. 2009;11(4):200-201.

29. Kallet RH. The role of inhaled opioids and furosemide for the treatment of dyspnea. Respir Care. 2007;52(7):900-910.

30. Yuengsrigul A, Chin TW, Nussbaum E. Decrease Cytokine Production from Human Peripheral Blood Mononuclear Cells (PBMCs) by Furosemide. Pediatr Res. 1996;39:15.

31. Xu B, Makris A, Thornton C, Ogle R, Horvath JS, Hennessy A. Antihypertensive drugs clonidine, diazoxide, hydralazine and furosemide regulate the production of cytokines by placentas and peripheral blood mononuclear cells in normal pregnancy. J Hypertens. 2006;24(5):915-922.

32. Manuscript submitted. 
33. University of North Carolina, Chapel Hill, Duke University, Eunice Kennedy Shriver National Institute of Child Health and Human Development, The Emmes Company LLC. Safety of Furosemide in Premature Infants at Risk of Bronchopulmonary Dysplasia (BPD). https ://ClinicalTrials .gov/show/NCT02527798. 2015.

34. Armed Forces Hospital Pakistan. Role of Salbutamol and Furosemide in TTN. https://ClinicalTrials . gov/show/NCT03208894. 2016.

35. University of Cologne. Trial on Treatment with Inhaled Furosemide of Preterm and Term Neonates with Transient Tachypnoea. https://ClinicalTrials.gov/show/NCT01407848. 2012.

36. McGill University. Inhaled Nebulized Furosemide \& Physical Activity-Related Breathlessness. https: //ClinicalTrials.gov/show/NCT01851980. 2016.

37. Oxford Brookes University. Specificity of Dyspnoea Relief with Inhaled Furosemide. https://ClinicalTrials . gov/show/NCT02881866. 2015.

38. Grogono JC, Butler C, Izadi H, Moosavi SH. Inhaled furosemide for relief of air hunger versus sense of breathing effort: a randomized controlled trial. Respir Res. 2018;19(1):181.

39. Moosavi SH, Binks AP, Lansing RW, Topulos GP, Banzett RB, Schwartzstein RM. Effect of inhaled furosemide on air hunger induced in healthy humans. Respir Physiol Neurobiol. 2007;156(1):1-8.

40. Nishino T, Ide T, Sudo T, Sato J. Inhaled furosemide greatly alleviates the sensation of experimentally induced dyspnea. Am J Respir Crit Care Med. 2000;161(6):1963-1967.

41. Alshehri M, Almegamesi T, Alfrayh A. Efficacy of nebulized furosemide in children with moderate attack of asthma. West Afr J Med. 2005;24(3):246-251.

42. Nuhoğlu C, Yaşar Kiliç M, Ceran O. Effectiveness of nebulized furosemide added to nebulized salbutamol in children with acute asthma. Allergol Immunopathol (Madr). 2006;34(2):54-58.

43. Ono Y, Kondo T, Tanigaki T, Ohta Y. Furosemide given by inhalation ameliorates acute exacerbation of asthma. J Asthma. 1997;34(4):283-289.

44. Pendino JC, Nannini LJ, Chapman KR, Slutsky A, Molfino NA. Effect of inhaled furosemide in acute asthma. J Asthma. 1998;35(1):89-93.

45. Chin T, Franchi L, Nussbaum E. Reversal of bronchial obstruction in children with mild stable asthma by aerosolized furosemide. Pediatr Pulmonol. 1994;18(2):93-98.

46. Banzett RB, Schwartzstein RM, Lansing RW, O'Donnell CR. Aerosol furosemide for dyspnea: High-dose controlled delivery does not improve effectiveness. Respir Physiol Neurobiol. 2018;247:24-30.

47. Voss TG, Gatti PJ, Fermin CD, Garry RF. Reduction of Human Immunodeficiency Virus Production and Cytopathic Effects. Virology. 1996;219:291-294.

48. Ulug ET, Garry RF, Bose HR. The role of monovalent cation transport in Sindbis virus maturation and release. Virology. 1989;172(1):42-50.

49. Hartley CE, Buchan A, Randall S, Skinner GR, Osborne M, Tomkins LM. The effects of lithium and potassium on macromolecular synthesis in herpes simplex virus-infected cells. J Gen Virol. 1993;74 (Pt 8):1519-1525.

50. Hartley C, Hartley M, Pardoe I, Knight A. Ionic Contra-Viral Therapy (ICVT); a new approach to the treatment of DNA virus infections. Arch Virol. 2006;151(12):2495-2501.

51. Rijsbergen M, Niemeyer-van der Kolk T, Hogendoorn G, et al. A randomized controlled proof-of-concept trial of digoxin and furosemide in adults with cutaneous warts. Br J Dermatol. 2019;180(5):1058-1068. 
52. Hung C-M, Peng C-K, Wu C-P, Huang K-L. Bumetanide attenuates acute lung injury by suppressing macrophage activation. Biochem Pharmacol. 2018;156:60-67.

53. Lan C-C, Peng C-K, Tang S-E, et al. Inhibition of Na-K-Cl cotransporter isoform 1 reduces lung injury induced by ischemia-reperfusion. J Thorac Cardiovasc Surg. 2017;153(1):206-215.

54. O'Connor BJ, Chung KF, Chen-Worsdell YM, Fuller RW, Barnes PJ. Effect of inhaled furosemide and bumetanide on adenosine 5'-monophosphate- and sodium metabisulfite-induced bronchoconstriction in asthmatic subjects. Am Rev Respir Dis. 1991;143(6):1329-1333.

55. Yeo CT, O'Connor BJ, Chen-Worsdell M, Barnes PJ, Chung KF. Protective effect of loop diuretics, piretanide and frusemide, against sodium metabisulphite-induced bronchoconstriction in asthma. Eur Respir J. 1992;(5):1184-1188.

56. Bianco S, Robuschi M, Vaghi A, Pieroni MG, Sestini P. Protective effect of inhaled piretanide on the bronchial obstructive response to ultrasonically nebulized H2O. A dose-response study. Chest. 1993;104(1):185188.

57. Hampel P, Römermann K, MacAulay N, Löscher W. Azosemide is more potent than bumetanide and various other loop diuretics to inhibit the sodium-potassium-chloride-cotransporter human variants hNKCC1A and hNKCC1B. Sci Rep. 2018;8(1):9877.

58. Jaques A, Daviskas E, Turton JA, et al. Inhaled mannitol improves lung function in cystic fibrosis. Chest. 2008;133(6):1388-1396.

59. Daviskas E, Anderson SD, Eberl S, Chan HK, Bautovich G. Inhalation of dry powder mannitol improves clearance of mucus in patients with bronchiectasis. Am J Respir Crit Care Med. 1999;159(6):1843-1848.

60. Nijs SB de, Fens N, Lutter R, et al. Airway inflammation and mannitol challenge test in COPD. Respir Res. 2011;12:11.

61. Chen D, Li X, Song Q, Hu C, Su F, Dai J. Hypokalemia and Clinical Implications in Patients with Coronavirus Disease 2019 (COVID-19): medRxiv 2020.02.27.20028530v1; 2020.

62. Lippi G, South AM, Henry BM. ANNALS EXPRESS: Electrolyte Imbalances in Patients with Severe Coronavirus Disease 2019 (COVID-19). Ann Clin Biochem. 2020:4563220922255.

63. Greenblatt DJ, Duhme DW, Allen MD, Koch-Weser J. Clinical toxicity of furosemide in hospitalized patients. Am Heart J. 1977;94(1):6-13.

64. Waskiw-Ford M, Wu A, Mainra A, et al. Effect of Inhaled Nebulized Furosemide (40 and $120 \mathrm{mg}$ ) on Breathlessness during Exercise in the Presence of External Thoracic Restriction in Healthy Men. Front Physiol. 2018;9:86.

65. Stone P, Rix, Kurowska A, Tookman. Re: nebulized furosemide for dyspnea in terminal cancer patients. J Pain Symptom Manag. 2002;24(3):274-275.

66. Li H, Liu L, Zhang D, et al. SARS-CoV-2 and viral sepsis: observations and hypotheses. The Lancet. 2020 .

\section{Figure Legends}

Figure 1: Structures of furosemide (A), piretanide (B), azosemide (C) and bumetanide (D); 3-HAA = 3hydroxyanthranilic acid.

Figure 2: Structure of mannitol. 

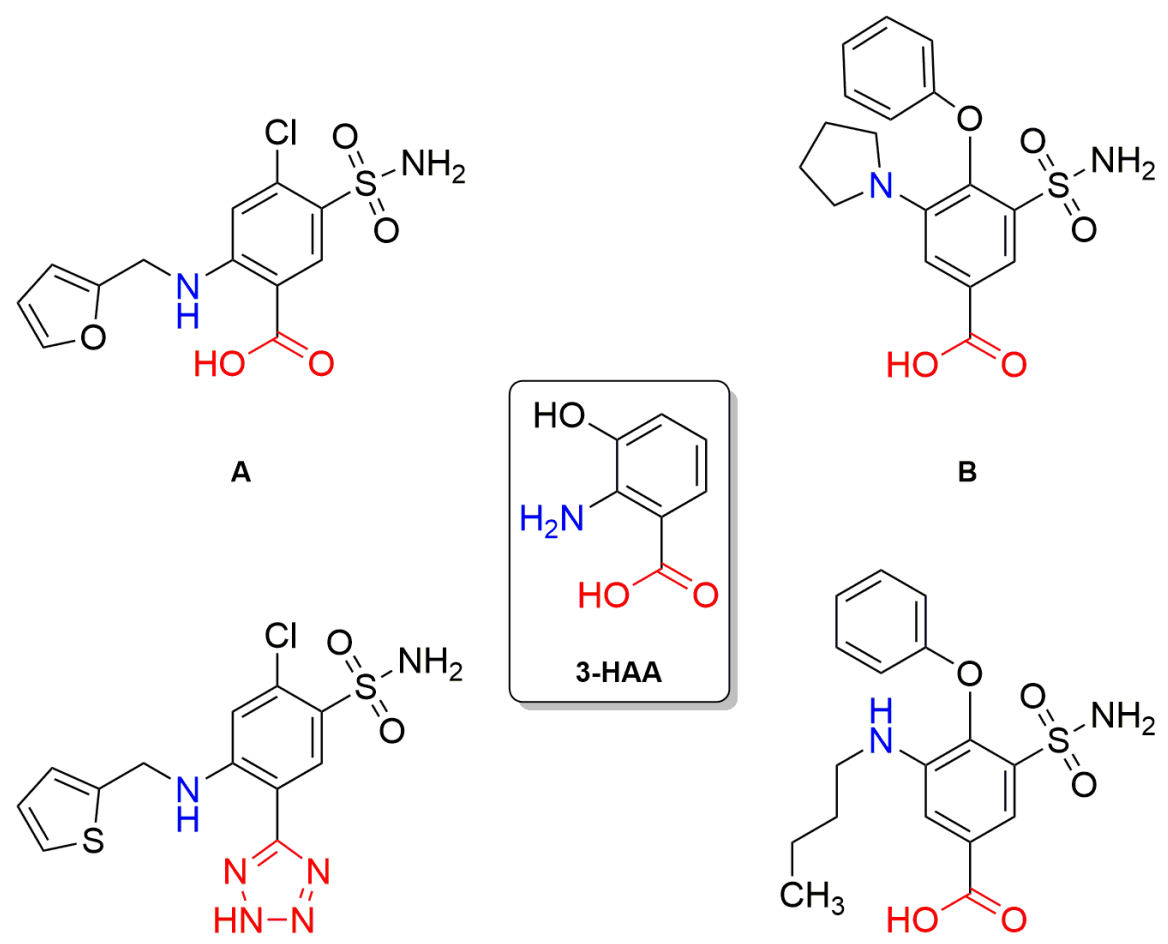

C

D

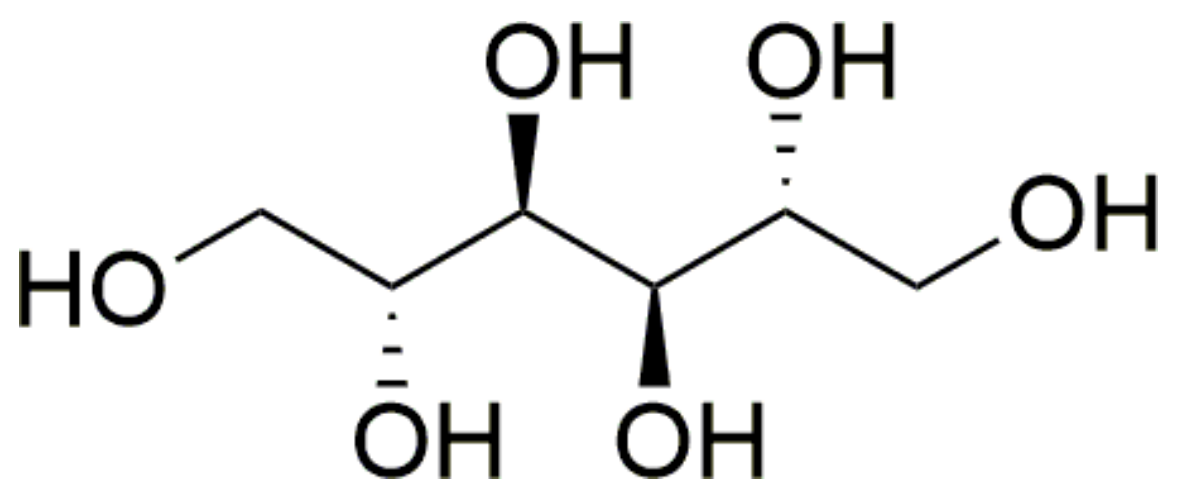

